\title{
VICTIMS OF BULLYING AMONG STUDENTS WITH A DISABILITY OR CHRONIC ILLNESS AND THEIR PEERS: A CROSS-NATIONAL STUDY BETWEEN IRELAND AND FRANCE
}

\section{List of authors}

Mariane Sentenac, $\mathrm{MSc}^{1}$ Aoife Gavin, $\mathrm{MA}^{2}$ Catherine Arnaud, $\mathrm{MD} \mathrm{PhD}^{1,3}$; Michal Molcho $\mathrm{PhD}^{2}$; Emmanuelle Godeau MD $\mathrm{PhD}^{1,4}$, Saoirse Nic Gabhainn, $\mathrm{PhD}^{2}$

${ }^{1}$ UMR Inserm U558; University Paul Sabatier, Toulouse, France

${ }^{2}$ Health Promotion Research Centre, School of Health Sciences, National University of Ireland Galway, Ireland

${ }^{3}$ Clinical epidemiology department, University hospital, Toulouse, France

${ }^{4}$ Service Médical du Rectorat, Toulouse, France

Corresponding author: Mariane Sentenac

Mailing: Hôpital Paule de Viguier, Inserm 558, 330 Avenue de Grande Bretagne, TSA 70034, 31049

Toulouse cedex 9, France

E-mail : mariane.sentenac@cict.fr

Phone number: ++33 567771393

Fax number: ++33 567771392 


\section{Source of support}

Financial support was obtained in 2008 from the ULYSSES exchange program (project $\mathrm{n}^{\circ} 18934 \mathrm{VJ}$ ). Expenses for the Irish researchers were funded by the national ministry for Health and Children and the Ulysses program of the Irish Research Council for Humanities and Social Science, and French researchers were funded by Égide, on behalf of the French Embassy. 


\begin{abstract}
:
Purpose: To explore bullying victimization among French and Irish students with a disability or chronic illness (D/CI) considering individual, social and family factors. We investigated this issue in France and Ireland because of the documented differences between these two countries on relevant contextual factors.
\end{abstract}

Methods: Data from 12,048 students aged 11, 13 and 15 years (50.1\% were boys) as part of the crossnational study 2006 Health Behaviour in School-aged Children (HBSC) were analyzed. Selfcompletion questionnaires were administered in classrooms; information on socio-demographic characteristics, bullying involvement, disability/chronic illness, school participation, social network and family were collected. Multivariate logistic regressions were performed with individual, social and family cofactors.

Results: Overall, the prevalence of bullying victimization was significantly higher in France than in Ireland (respectively $34.2 \%(33.1-35.5)$ and $25.9 \%$ (24.5-27.4)). Youngest were more likely to report victimization; and no gender differences were observed. In both countries, students with $\mathrm{D} / \mathrm{CI}$ are significantly more likely to report that they have been bullied than students without $\mathrm{D} / \mathrm{CI}$ and a significant additional risk of being bullied was found when students reported D/CI with restriction in school participation. Regardless of country and D/CI status, being bullied was significantly associated with weaker social support and difficulty of communication with fathers, with even stronger associations among students with D/CI.

Conclusion: Adolescents with D/CI are more likely to victimized than their peers, with a similar risk in both countries. Besides individual, social and family factors are consistently associated to bullying victimization across countries. These results will guide future anti-bullying prevention programs. 
KEY WORDS: students; bullying; disability; chronic illness; school participation; social network; family 


\section{TEXT:}

\section{INTRODUCTION}

Bullying is a common problem among children and adolescents and its description, prediction and prevention have motivated many researchers and educators [1,2]. Prevalence studies have consistently reported that a significant number of school-aged children are involved in bullying, even if its prevalence varies across countries [3-5]. A recent international study reported significant decreases in bullying behaviors over the past decade in most countries studied, a positive development in the context of existing prevention activities [6].

The Olweus definition of bullying is widely used in the literature. Olweus defined bullying as negative physical or verbal actions that have hostile intent, cause distress to victims, are repeated and involve a power differential between bullies and victims. Thus three important elements define bullying: repetition, harm and unequal power [7].

Recent studies have focused on understanding the conditions surrounding bullying, highlighting the need to consider contextual models to examine positive and negative adolescent behaviors [8-11]. Some socio-demographic, family and social factors have been found to be consistently associated with victimization but few studies have taken them into account together, or explicitly examined their interactions $[3,10,12]$. Previous studies have reported that male $[1,5,13]$, younger children, $[1,3,5,10]$, those living in a non-intact family $[5,13,14]$, with parents with low socio-economic [13] or educational levels [3,5], who experience difficulties in communicating with their parents [14], poorer relationship with parents $[10,13]$ or classmates [1,14], poorer social support [3], social isolation [14], fewer friends [10], poorer school climate [13], lower school involvement and performance [14], are more victimized. 
Knowledge of bullying among students with a disability or a chronic illness (D/CI) is sparse. Some studies have documented higher rates of bully victimization among adolescents with $\mathrm{D} / \mathrm{CI}[5,13,15,16]$, but they tend to focus on specific conditions, and show that specific groups of children (children with learning disabilities [17], attention-deficit/hyperactivity disorder [12], or cerebral palsy [18]) are at greater risk of being victimized. The hypothesis that adolescents different in appearance or in behavior are more likely be bullied has also been investigated $[13,19,20]$. However studies exploring bullying among adolescents with D/CI with a multi-contextual explanatory approach are rare [13]. In her review, Stassen-Bergen [2] argues that there is not only one cause of bullying, but rather that the interaction between the chronic condition and the environment of the adolescent best predicts bullying. A previous study found that children with visible disability were overall more likely to be bullied, but this association was not significant once elements of the child's environment were included in the analysis [19]. The negative impact of D/CI on children's participation in recreational and sporting activities has been documented, highlighting a higher risk of social isolation [21], while others have described bullying as an environmental barrier to full social participation for children with or without disability $[22,23]$.

The aims of this paper are 1) to describe the frequency of bullying victimization at school in students according to their D/CI status in Ireland and France; 2) to compare the relative strength of the associations between socio-demographic, social network, family factors and bullying victimization between students with or without D/CI across these countries, hypothesizing environment at several levels may influence students behaviors differently for students with D/CI compared to others; and 3) to document the additional risk of bullying victimization associated with the level of D/CI. We investigated this issue in Ireland and France as two contrasting environments which may influence bullying among students with D/CI: first, there is a large cross-national variation in the frequency of 
bullying behaviors, Ireland ranking lower than France [4]; and second, policies advocating inclusive education of students with disability into mainstream schools are more recent in France than in Ireland.

\section{METHODS}

\section{Sample}

This study utilizes data from the Irish and French 2006 Health Behavior in School-aged Children (HBSC) WHO cross-national collaborative study. Research teams in participating countries followed the same protocol [24] regarding question ordering, translation guidelines, comprehensive guidance on sampling and data collection procedures, so to facilitate subsequent cross-national analyses. The population studied consists of nationally representative samples of students (random design, geographical and/or school grades stratification, clustering into schools and classrooms), in three age groups (mean aged 11.5, 13.5 and 15.5) broadly covering the onset and the middle years of adolescence, when changes occur and decisions are beginning to be made. Participation was anonymous and voluntary, consent from parents and students was obtained. Each country obtained approval to conduct the survey from the relevant institutional review board or equivalent regulatory institution. The response rates at school and student levels respectively were $63 \%$ and $83 \%$ in Ireland; $79 \%$ and $81 \%$ in France.

\section{Measurement}

Data were collected using standardized self-completion questionnaires administered in class. The questionnaire was developed by an interdisciplinary research group from the participating countries and a translation/back translation procedure was used to guarantee language equivalence.

Questions about bullying were those developed by Olweus [7] and were preceded by a standardized definition in order to ensure similar comprehension across countries. Participants were asked to report 
how frequently they had been bullied at school in the past couple of months. The five response options ranged from "I have not been bullied in the past couple of months" to "several times a week". For analyses, responses were dichotomized into "never" vs. "at least once in the past couple of months".

To identify children with D/CI, a yes/no question, adapted from Finnish and Canadian 2001/2002 HBSC surveys, was used [25] : "Do you have a long-term illness, disability, or medical condition (like diabetes, arthritis, allergy or cerebral palsy) that has been diagnosed by a doctor?" A subsequent question allowed identification of children for whom their D/CI restricted attendance or participation at school [25]. Students were then classified into three mutually exclusive categories as non D/CI children, $\mathrm{D} / \mathrm{CI}$ without restriction in participation and $\mathrm{D} / \mathrm{CI}$ with restriction in participation.

The association of three independent groups of factors (socio-demographic, social network and family factors) with bullying victimization was investigated. Socio-demographic factors included age, gender and family affluence, the latter assessed by the validated Family Affluence Scale [26] through a composite score used as an ordinal indicator of affluence: high, middle and low. The quality of social network was investigated by two indicators: one on communication with same-sex friends and a threeitem scale measuring social support from classmates developed for the study (with a global score of classmate support ranging from 0 to 12 , dichotomized into strong (12-6) vs weak (6-0) support). Family factors were represented by family structure (living with both biological parents or not) and communication with mother and father considered separately. The same item was used to measure ease of communication with mother, father and same-sex friend ("How easy is it for you to talk to the following persons about things that really bother you?") coded on a five-point Likert scale. Ease of communication variables were dichotomized into "very easy/easy" and "difficult/very difficult", while 
the response "Don't have or see this person" was recoded in missing. More information related to these items is available in Currie [4].

\section{Statistical analyses}

All analyses were carried out separately for each country; all estimates were adjusted according to the structure of the sampling frame. Univariate analyses were performed to describe the distribution of the three relevant groups of independent variables (socio-demographic, social network and family factors), and Pearson's chi-square tests were used to explore differences across countries. Frequencies of being bullied were compared by age, gender and D/CI status using Pearson's chi-square statistics. No significant difference was found regarding missing data on bullying victimization according to disability level $(1.4 \%$ missing data in No D/CI, $1.0 \% \mathrm{D} / \mathrm{CI}$ without restriction, $1.9 \% \mathrm{D} / \mathrm{CI}$ with restriction).

To explore and compare the strength of the associations between bullying victimization and sociodemographic, social network, family factors between students with or without D/CI across countries, separate logistic regression models were performed for students reporting a D/CI and for others in each country. The interaction terms were tested between country and all cofactors to explore cross-country differences. To estimate the additional risk of being bullied associated with reported D/CI, with or without restriction in school participation, an additional logistic regression analysis was performed, adjusted for all cofactors and country. This "level of disability" variable in three categories was considered a proxy for the severity of the disability, and this interpretation was supported by preliminary analyses that revealed a linear relation with the risk of being bullied. Level of disability was tested as a dichotomous variable as well as an ordinal variable, which increases the power of the estimation. 
Odds Ratios (ORs) for reporting being bullied at least once in the past couple of months were calculated. Confidence Intervals (CIs) were computed at the $95 \%$ level and statistical significance was established at $\mathrm{p}<0.05$. All analyses were performed using STATA 9.2 [27]. 


\section{RESULTS}

The sample consisted of 4,894 students in Ireland and 7,154 students in France. Table 1 shows the characteristics of the samples by country. The percentage of students reporting D/CI was higher in Ireland $(20.6 \%)$ than in France $(16.6 \%)(\mathrm{p}<0.001)$. Compared to the Irish, French students were significantly more likely to report negative social network (in terms of communication with same-sex friends and classmate support) and more difficulties in communication with their parents. They were also less likely to live with their two parents.

A very consistent pattern emerged, with bullying behaviors more often reported in France than in Ireland in all age (results not shown), gender and D/CI status groups (Table 2). Overall, 34.2\% (33.135.5) of students reported being bullied in France vs. $25.9 \%(24.5-27.4)$ in Ireland $(\mathrm{p}<0.001)$. In both countries, and regardless D/CI status, the youngest students were significantly more likely to report being bullied than older students; and there were no significant gender differences in being bullied. Students with D/CI were significantly more likely to report being bullied in both countries (except among Irish boys).

Table 3 presents the associations between bullying victimization and the three independent groups of factors: socio-demographic, social network and family factors, by D/CI status and by country. Regardless of country and D/CI status, weak classmate support was significantly associated with being bullied, and this association tended to be stronger for students reporting D/CI. A particularly strong association was found between being bullied and students reporting D/CI both in Ireland: OR 3.5 (2.06.1) and in France: OR 4.0 (2.6-6.1). Ease communication with same-sex friends was found to be significantly positively associated with bullying victimization only among students without D/CI. Regarding family factors, ease communication with father was consistently, inversely and significantly 
associated with being bullied in both countries. Ease communication with mother was not found to be significantly associated with bullying victimization, except in Ireland for students without D/CI: OR $1.4(1.1-1.7)$.

Table 4 demonstrates the associations between being bullied and the level of D/CI adjusted for all other factors. In both countries, students who reported D/CI with restricted participation at school had a significantly higher risk of being bullied (fully adjusted model: OR 1.8 (1.4-2.4)), compared with those with D/CI without restriction: OR 1.3 (1.2-1.4). The interaction between communication with mother and country was statistically significant $(\mathrm{p}=0.006)$, indicating that among students who reported communicating more easily with their mother, French students were significantly more victims of bullying than Irish students: OR 1.4 (1.2-1.6). No cross-country difference was found among students reporting difficulty in communication with mother.

\section{DISCUSSION}

Our findings confirm cross-national differences in bullying victimization with a higher prevalence in France than in Ireland [4], even after controlling for a range of factors previously found to be associated with bullying behaviors. In both countries, students with $\mathrm{D} / \mathrm{CI}$ were significantly more likely to report that they had been bullied than students without $\mathrm{D} / \mathrm{CI}$, and a $30 \%$ additional risk of being bullied was found when students reported both D/CI and restriction in school participation. Being bullied was consistently associated with weaker social support and difficulty of communication with fathers, with even stronger associations among students with D/CI.

Two factors may help explain the cross-national variation between countries: differences in the interpretation of the bullying concept and cultural or contextual differences. Stassen Berger [2] 
suggests that variation in the interpretation of the term bullying and the understanding of the concept could help to explain some variation across countries reported in the literature on bullying. However, the preamble in our questionnaire describes bullying in a complete and clear fashion and thus provides a common operational definition, allowing confidence in these cross-national comparisons. The variations observed in bullying rates may well stem from different educational systems or different national or school level policies related to bullying prevention. School bullying is well known in Scandinavian and Anglo-Saxon countries, where many prevention programs have been implemented, since many years. In Ireland all schools have been required to take action against bullying and have a locally agreed and implemented anti-bullying policy. In contrast, the term "school violence" appeared in France only ten years ago, without an emphasis on bullying or being specific about 'power differentials' inherent in bullying behavior. In addition, anti-hazing legislation exists in France since 1997 but prevention programs are aimed at graduate students. Molcho et al. have shown that in many countries where national prevention is consistent, the prevalence of bullying behaviors has recently decreased [6], and this has been the case in Ireland. A decrease was also observed in France, which may be attributed to the observed growing media coverage of school violence in general.

Despite differences in bullying rates between both countries, we found that students with D/CI are more likely to be victimized with a similar risk in Ireland and in France. In many Western countries, children with $\mathrm{D} / \mathrm{CI}$ have become increasingly integrated into mainstream schools assuming that inclusive education encourages the acceptance of children with disability by their peers. In both France and Ireland, education systems favor mainstreaming and offer a variety of special needs services, but the concept of truly inclusive education is a relatively new in both education systems [28]. In France the legislative framework on disability was recently reformed with the Act for Equal Right and Opportunities, Participation and Citizenship of Disabled People of 11 February 2005 recognizing the 
right for any child with disability to attend his/her local primary or secondary school. In Ireland the Education Act 1998 requires the provision of a quality education to each person in the country, while the 2004 Education for Persons with Special Needs Act specifies that education must be inclusive, unless there are particular reasons why a specialized placement is required for an individual child.

Our study explored factors associated with bullying victimization among adolescents with and without D/CI, using a global approach taking into account individual, social network and family factors, in two countries with contrasting contexts. We found considerable similarities between countries and between D/CI status groups in the factors associated with being bullied. Consistent with previous studies, we found that younger students were more likely than older students to report that they have been bullied $[1,3,5,29,30]$, this holds true for D/CI students as well. Social networks, in terms of social skills [31], number and quality of friends [2] and friendship quality [32], have been described as a moderator of risk factors in predicting peer victimization. More specifically, some studies have shown that some chronic conditions, causing lower youth involvement in social activities and depleting their social network, place students at higher risk of being bullied [33]. Students with D/CI may be more frequently absent from school if they are receiving treatment or special lessons; and this can affect their social standing and friendships [33]. With a stronger influence of classmate support on victimization among adolescents with D/CI, our findings are consistent with this literature. Our results in relation to family factors are more surprising, and somewhat controversial, with the strong association between ease of communication with fathers and bullying victimization, and a less consistent association for communication with mothers. To our knowledge, the specific role of fathers in relation with bullying victimization has not been explored, but rather the familial environment through either both parents or mothers only $[5,13,15,34]$. Some studies have demonstrated that fathers' have a unique contribution 
to their children's behaviors, irrespective of the mothers role [35], and relationships with fathers have been shown to be of particular importance when the father is not resident in the main family home [36]. In addition and in accordance with bullying literature showing that victims of bullying are also often bullies $[1,10,14,16]$, we carried out a sensibility analysis to check if students reporting D/CI were more victims that bully-victims, and if they had a different profile in terms of social and family context: no differences were found.

We also studied the additional risk of being bullied associated with the level of disability adjusted for all cofactors. We hypothesized that the level of disability was more severe when students reported that their D/CI had an impact on their school participation compared those reporting D/CI without such a restriction in participation, and our results confirm this. However, additional quantitative and qualitative studies are required to help document the nature of the relationships between all these dimensions.

The current paper is based on large representative samples in two countries, using standardized research methods that had been tested many times in previous HBSC studies, language equivalence and a common operational definition of bullying. France and Ireland were chosen for analysis primarily because of the differences in reported prevalence of school bullying behaviors as known in previous waves of the HBSC studies [4]. It should be noted that the samples also differ on other indicators: higher rates of D/CI students and lower levels of family affluence in Ireland and more children not living with both parents in France. Another strength of this study is its relevance to public health and its potential contribution to prevention efforts towards a vulnerable population. 
However, this study relies on self-reported data for both bullying behavior and D/CI status. Selfreported D/CI is significantly more prevalent in Ireland than in France. This could stem from higher level of integration of children with $\mathrm{D} / \mathrm{CI}$ in mainstream education in Ireland or from a different understanding of the question, despite the examples given. Prevalence data on chronic conditions among adolescents, based on others sources, are not available for comparison neither in France nor in Ireland. However, previous Canadian results suggest that chronic conditions can be under-reported by children compared to parents $[25,37]$. In line with some previous findings indicating that allergy and asthma are the most commonly reported chronic conditions in childhood $[16,37,38]$, we assumed that in our sample, most students reporting $\mathrm{D} / \mathrm{CI}$ without restriction have such illnesses, and that a higher proportion of students with most severe chronic illness and disability are to be found among those reporting D/CI with restricted participation at school. In our data, difference across countries of prevalence was significant for students reporting D/CI with restricted participation (France: 3.1\% (2.73.5) vs Ireland: $5.5 \%(4.9-6.2)$ but not for those reporting D/CI without restriction (France: 15.2\% (12.4-14.0) vs Ireland: $13.0 \%(12.1-14.0)$. This could mirror the fact that the integration of students with more severe disability is more advanced in Ireland. Qualitative work would help in further understanding these differences. Another limitation of the present study is related to the general measure of bullying that was used: we cannot distinguish between different forms or types of bullying, such as physical or social exclusion bullying. Qualitative studies on students' perceptions of bullying could be particularly useful in helping to understand any cross-national differences in bullying that may exist.

Nansel et al. [1] highlighted that young people who are bullied generally have higher levels of insecurity, anxiety, depression, loneliness, unhappiness, physical and mental symptoms and lower selfesteem. Another study has shown that students who have been bullied are more likely to have more fragile health at adulthood [39]. Future prevention and intervention programs should pay more attention 
to students with $\mathrm{D} / \mathrm{CI}$ whose number is rising in schools and who are especially vulnerable to bullying. Consequences for these young people are multiple: more social isolation, less participation in activities at school, more negative self-perceptions as well as potential effects on both objective and subjective components of health. We have shown that contextual factors were associated with reports of bullying victimization, and these should be considered for future strategies to prevent such bullying at school and in other settings. Vignes et al. [40] found that factors related to disability knowledge were significantly associated to better attitudes among students. Thus, we also recommend the inclusion of a disability component in future anti-bullying programs and policies, and to take into account students' environment, i.e., peers, teachers, and family members.

In conclusion, our study highlights the need to pay attention to the particular issues for children with $\mathrm{D} / \mathrm{CI}$ associated with bullying victimization, and these findings deserve qualitative exploration crossnationally. This study also suggests that there is a need to further investigate the possible health consequences of being bullied among students with $\mathrm{D} / \mathrm{CI}$ as they seem to cumulate vulnerabilities associated with being bullied as well as or in combination with their existing chronic conditions. 


\section{REFERENCES}

1. Nansel T.R., Overpeck M., Pilla Ramani S., et al. Bullying Behaviors Among US Youth: Prevalence and Association With Psychosocial Adjustment. JAMA 2001 April 25, 2001;285(16):20942100.

2. Stassen Berger K. Update on bullying at school: Science forgotten? Developmental Review 2007;27(1):90-126.

3. Analitis F., Velderman M. K., Ravens-Sieberer U., et al. Being Bullied: Associated Factors in Children and Adolescents 8 to 18 Years Old in 11 European Countries. Pediatrics 2009 Feb;123(2):569-577.

4. Currie C., Nic Gabhainn S., Godeau E., et al., eds. Inequalities in young people's health: international report from the HBSC 2005/06 survey. Copenhagen: WHO Regional Office for Europe, 2008

5. Nordhagen R., Nielsen A., Stigum H., et al. Parental reported bullying among Nordic children: a population-based study. Child Care Health Dev 2005 Nov;31(6):693-701.

6. Molcho M., Craig W., Due P., et al. Cross-national time trends in bullying behaviour 19942006: findings from Europe and North America. Int J Public Health 2009 Sep;54 Suppl 2:225-234.

7. Olweus D. Bullying at School: What We Know and What We Can Do: Blackwell Publishers, 1993.

8. Barboza G.E., Schiamberg L.B., Oehmke J., et al. Individual characteristics and the multiple contexts of adolescent bullying: an ecological perspective. J Youth Adolesc 2009 Jan;38(1):101-121.

9. Limber S.P. Addressing youth bullying behaviors. In: Fleming M TK, editor. Proceedings Educational Forum on Adolescent Health: Youth Bullying; 2002; Chicago: American Medical Association; 2002. p. 48.

10. Wang J, Iannotti RJ, Nansel TR. School Bullying Among Adolescents in the United States: Physical, Verbal, Relational, and Cyber. Journal of Adolescent Health 2009;45(4):368-375.

11. Youngblade L.M., Theokas C., Schulenberg J., et al. Risk and promotive factors in families, schools, and communities: A contextual model of positive youth development in adolescence. Pediatrics 2007;119:S47-S53.

12. Montes G., Halterman J.S. Bullying among children with autism and the influence of comorbidity with ADHD: a population-based study. Ambul Pediatr 2007 May-Jun;7(3):253-257. 
13. Pittet I., Berchtold A., Akre C., et al. Are adolescents with chronic conditions particularly at risk of bullying? Arch Dis Child 2009 Mar 22.

14. Spriggs A.L., Iannotti R.J., Nansel T.R., et al. Adolescent Bullying Involvement and Perceived Family, Peer and School Relations: Commonalities and Differences Across Race/Ethnicity. J Adolesc Health 2007;41(3):283-293.

15. Gortmaker S.L., Walker D.K., Weitzman M., et al. Chronic Conditions, Socioeconomic Risks, and Behavioral-Problems in Children and Adolescents. Pediatrics 1990 Mar;85(3):267-276.

16. Van Cleave J., Davis M.M. Bullying and Peer Victimization Among Children With Special Health Care Needs. Pediatrics 2006 October 1, 2006;118(4):e1212-1219.

17. Nabuzoka D., Smith P.K. Sociometric status and social behaviour of children with and without learning difficulties. J Child Psychol Psychiatry 1993 Nov;34(8):1435-1448.

18. Nadeau L., Tessier R. Social adjustment of children with cerebral palsy in mainstream classes: peer perception. Dev Med Child Neurol 2006 May;48(5):331-336.

19. Dawkins J.L. Bullying, physical disability and the paediatric patient. Dev Med Child Neurol $1996 \mathrm{Jul} ; 38(7): 603-612$.

20. Sweeting H, West P. Being different: correlates of the experience of teasing and bullying at age 11. Research Papers in Education 2001;16:225-246.

21. Yeo M., Sawyer S. Chronic illness and disability. BMJ 2005 Mar 26;330(7493):721-723.

22. Law M., Petrenchik T., King G., et al. Perceived environmental barriers to recreational, community, and school participation for children and youth with physical disabilities. Arch Phys Med Rehabil 2007 Dec;88(12):1636-1642.

23. Mihaylov SI, Jarvis SN, Colver AF, et al. Identification and description of environmental factors that influence participation of children with cerebral palsy. Developmental Medicine \& Child Neurology 2004;46(5):299-304.

24. Roberts C., Freeman J., Samdal O., et al. The Health Behaviour in School-aged Children (HBSC) study: methodological developments and current tensions. International Journal of Public Health 2009;54(0):140-150.

25. Raman SR, Boyce WF, Pickett W. Associations Between Adolescent Risk Behaviors and Injury: The Modifying Role of Disability. Journal of School Health 2009;79(1):8-16.

26. Currie C, Molcho M, Boyce W, et al. Researching health inequalities in adolescents: The development of the Health Behaviour in School-Aged Children (HBSC) Family Affluence Scale. Social Science \& Medicine 2008 Mar;66(6):1429-1436. 
27. Stata Corp, ed. STATA Corporation, Stata Statistical Software: Release 9. USA, 2005.

28. Tisdall K., ed. National contexts affecting the lives of disabled children in Denmark, France, Germany, Ireland, Italy, Sweden and UK (England and Northern Ireland). Newcastle NE2 4HQ: University of Newcastle upon Tyne, Robinson Library, 2006.

29. Due P, Holstein BE, Lynch J, et al. Bullying and symptoms among school-aged children: international comparative cross sectional study in 28 countries. Eur J Public Health 2005 April 1, 2005;15(2):128-132.

30. Hay DF, Payne A, Chadwick A. Peer relations in childhood. Journal of Child Psychology and Psychiatry 2004;45(1):84-108.

31. Fox CL, Boulton MJ. The social skills problems of victims of bullying: Self, peer and teacher perceptions. British Journal of Educational Psychology 2005 Jun;75:313-328.

32. Bollmer J. M., Milich R., Harris M. J., et al. A friend in need - The role of friendship quality as a protective factor in peer victimization and bullying. Journal of Interpersonal Violence 2005 Jun;20(6):701-712.

33. Lightfoot J., Wright S., Sloper P. Supporting pupils in mainstream school with an illness or disability: young people's views. Child: Care, Health and Development 1999;25(4):267-284.

34. Baker K, Donelly M. The Social Experiences of Children with Disability and the Influence of Environment: a framework for intervention. Disability \& Society 2001;16(1):71 - 85

35. Amato P. R., Rivera F. Paternal involvement and children's behavior problems. Journal of Marriage and the Family 1999 May;61(2):375-384.

36. Amato P.R., Gilbreth J.G. Nonresident fathers and children's well-being: A meta-analysis. J Marriage Fam 1999;61(3):557-573.

37. McDougall J, King G, De Wit D, et al. Chronic physical health conditions and disability among Canadian school-aged children: a national profile. Disability and Rehabilitation 2004;26(1):35-45.

38. Svavarsdottir EK, Orlygsdottir B. Health-related quality of life in Icelandic school children. Scandinavian Journal of Caring Sciences 2006;20(2):209-215.

39. Allison S., Roeger L., Reinfeld-Kirkman N. Does school bullying affect adult health? Population survey of health-related quality of life and past victimization. Australian and New Zealand Journal of Psychiatry 2009;43(12):1163-1170.

40. Vignes C., Godeau E., Sentenac M., et al. Determinants of students' attitudes towards peers with disabilities. Dev Med Child Neurol 2009 Jun;51(6):473-479. 
TABLE 1. Comparison of socio-demographic, social network and family characteristics by country

\begin{tabular}{|c|c|c|c|}
\hline & $\begin{array}{c}\text { Ireland } \\
(\mathbf{N}=\mathbf{4 , 8 9 4 )} \\
n(\%)\end{array}$ & $\begin{array}{c}\text { France } \\
(\mathbf{N}=7,154) \\
n(\%)\end{array}$ & p-value \\
\hline \multicolumn{4}{|l|}{ Socio-demographic factors } \\
\hline \multicolumn{4}{|l|}{ Gender } \\
\hline Girls & 2,417 (49.4) & $3,596(50.3)$ & \multirow{2}{*}{ ns } \\
\hline Boys & $2,477(50.6)$ & $3,558(49.7)$ & \\
\hline \multicolumn{4}{|l|}{ Age } \\
\hline 15 years old & $1,685(34.8)$ & $2,222(31.1)$ & \multirow{3}{*}{$<0.05$} \\
\hline 13 years old & $1,785(36.9)$ & $2,425(34.0)$ & \\
\hline 11 years old & $1,370(28.3)$ & $2,493(34.9)$ & \\
\hline \multicolumn{4}{|l|}{ Family affluence } \\
\hline High & $932(20.4)$ & $3,432(49.6)$ & \multirow{3}{*}{$<0.001$} \\
\hline Medium & $2,559(56.2)$ & $2,642(38.1)$ & \\
\hline Low & $1,065(23.4)$ & $849(12.3)$ & \\
\hline \multicolumn{4}{|l|}{ Disability/chronic illness } \\
\hline No D/CI & $3,848(81.5)$ & $5,930(83.8)$ & \multirow{3}{*}{$<0.001$} \\
\hline $\mathrm{D} / \mathrm{CI}$ without restriction & $615(13.0)$ & $931(13.1)$ & \\
\hline $\mathrm{D} / \mathrm{CI}$ with restriction & $260(5.5)$ & $220(3.1)$ & \\
\hline \multicolumn{4}{|c|}{ Social network factors } \\
\hline \multicolumn{4}{|c|}{ Communication with same sex friends } \\
\hline Easy or very easy & $3,657(82.5)$ & 4,909 (77.9) & \multirow{2}{*}{$<0.001$} \\
\hline Not easy & $707(17.5)$ & $1,391(22.1)$ & \\
\hline \multicolumn{4}{|l|}{ Weak classmate support } \\
\hline No & $4,375(91.2)$ & $6,119(87.9)$ & \multirow{2}{*}{$<0.001$} \\
\hline Yes & $423(8.8)$ & $845(12.1)$ & \\
\hline \multicolumn{4}{|l|}{ Family factors } \\
\hline \multicolumn{4}{|l|}{ Family structure } \\
\hline Two parents & 3,727 (80.6) & $5,164(73.4)$ & \multirow{2}{*}{$<0.001$} \\
\hline Others & $899(19.4)$ & 1875 (26.6) & \\
\hline \multicolumn{4}{|l|}{ Communication with mother } \\
\hline Easy or very easy & $3,732(82.3)$ & 4,983 (74.1) & \multirow{2}{*}{$<0.001$} \\
\hline Not easy & $805(17.7)$ & $1,741(25.9)$ & \\
\hline \multicolumn{4}{|l|}{ Communication with father } \\
\hline Easy or very easy & $2,952(67.3)$ & $3,404(53.1)$ & \multirow{2}{*}{$<0.001$} \\
\hline Not easy & $1,432(32.7)$ & $3,004(46.9)$ & \\
\hline
\end{tabular}




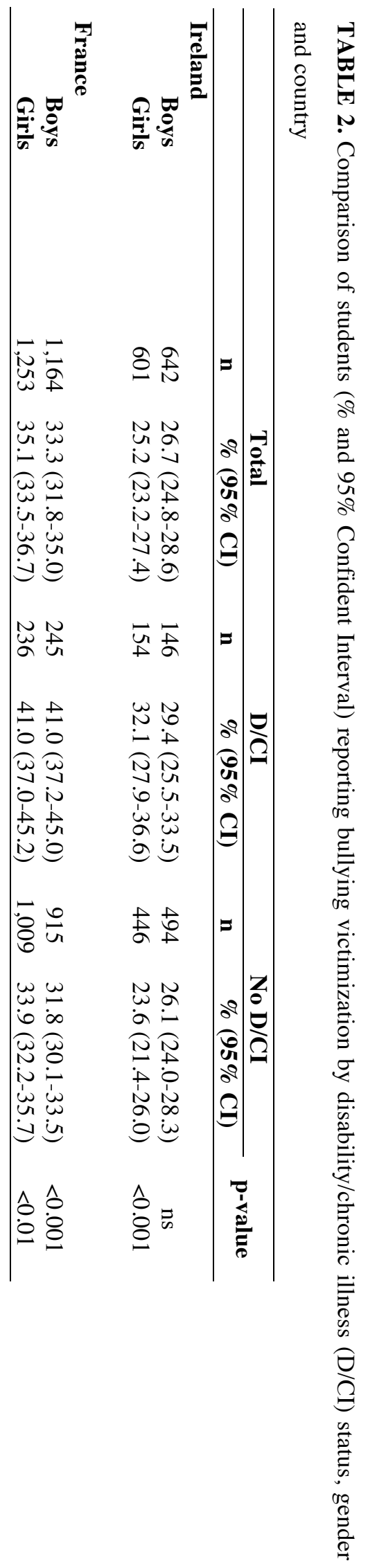




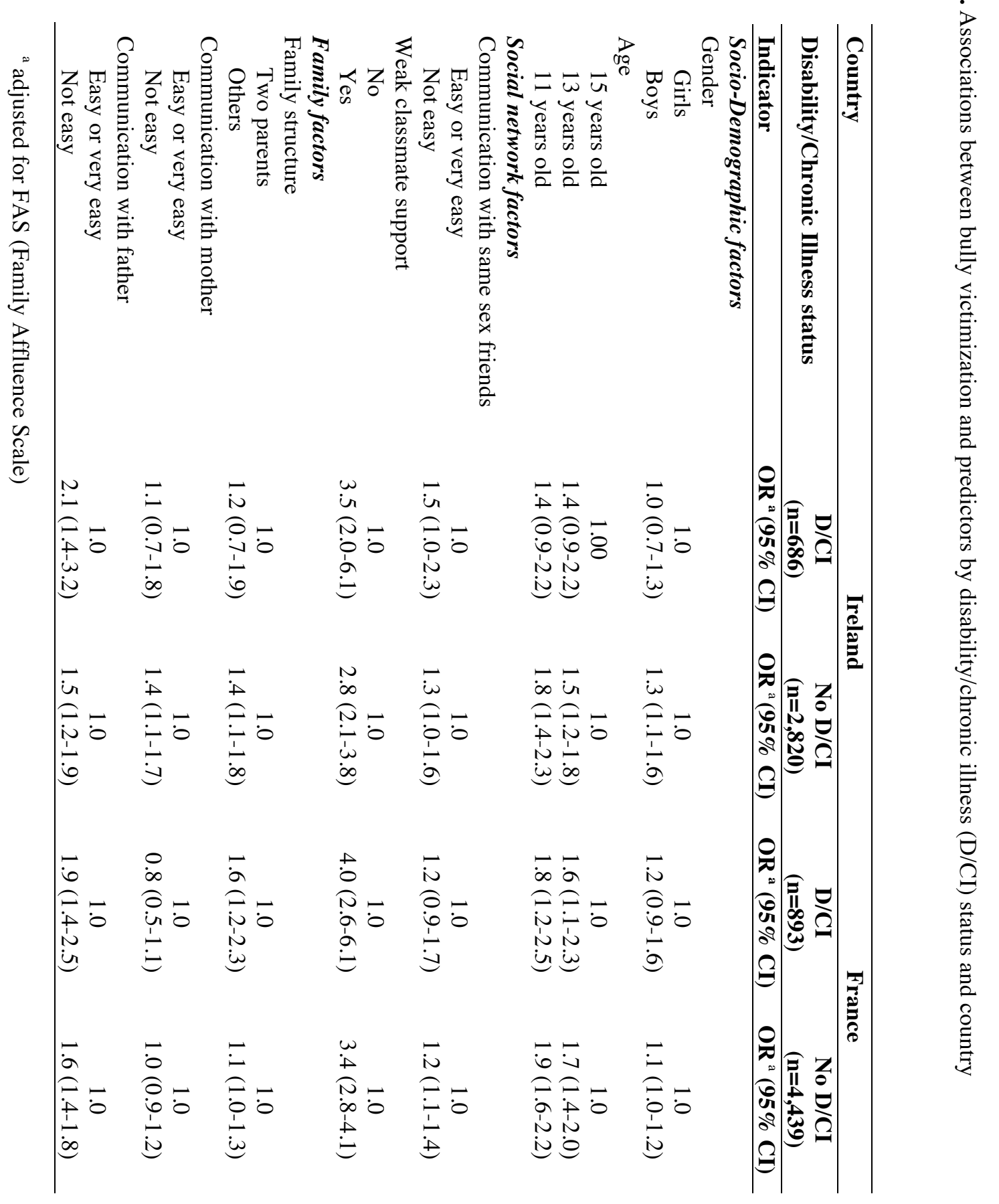




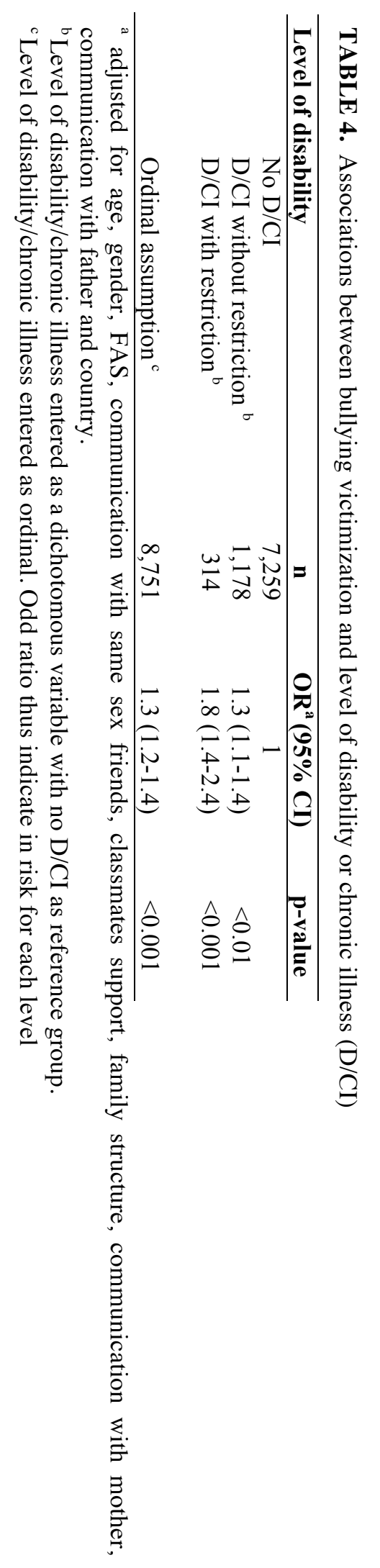

